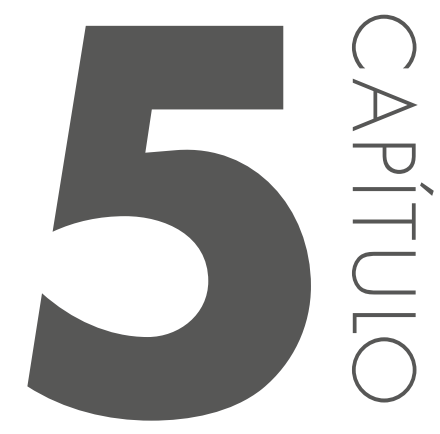

\title{
ALLAN KARDEC E O LÉXICO DA DOUTRINA ESPIRITA
}

Celina Márcia de Souza Abbade* (Universidade do Estado da Bahia)

*Professora Titular do Programa de Pós-Graduação em Estudo de Linguagens da Universidade do Estado da Bahia 


\section{Introduc̣ão}

Doutrina espiritualista cristã, o Espiritismo abrange os campos da filosofia, ciência e religião. Seus princípios mesclam o cristianismo a partir da caridade de Jesus Cristo, o budismo com o dogma das reencarnações, o darwinismo com a teoria evolucionista das espécies e com outras crenças da época que geraram diversas filosofias.

Nascido em meio ao florescimento das ciências experimentais do século XIX, o Espiritismo surge já em contradição ao tradicionalismo religioso da época que era contrário às manifestações científicas fora de seu cânone.

O termo Espiritismo ficou conhecido a partir da publicação consecutiva de cinco obras iniciadas em 1857 por seu codificador, Allan 
Kardec, pseudônimo utilizado pelo pedagogo Hippolyłe Léon Denizard Rivaill.

O esforço de Allan Kardec para dar um caráter particular e distinto das correntes espiritualistas do século XIX, ao expor as novas ideias designadas por ele mesmo de espíritas, levou o mesmo a preocuparse com a sua terminologia e criar palavras visando tornar mais claro o que estava sendo apresentado. Isso levou inclusive ao nome da doutrina, Espiritismo, criado para se opor a palavra já existente Espiritualismo, ainda que o Espiritismo seja mais uma doutrina espiritualista: Espiritismo designa exclusivamente os princípios codificados por Allan Kardec para mais uma doutrina espiritualisma, cuja crença maior é a de que exista algo além da matéria.

Nascido em Lyon, na França, a 03 de outubro de 1804, o autor não utilizou o seu nome ilustre e conhecido de pedagogo e cientista à época, mas um nome obscuro que teria sido, segundo os espíritos, seu nome em uma de suas encarnações passadas entre os druidas, encarnação em que se preparava ativamente para a missão espírita: Allan Kardec. Assim, o nome obscuro acabou por suplantar o nome ilustre. Essas obras foram publicadas em uma época de grandes transformações sociais, filosóficas, políticas e linguísticas, período do surgimento das ciências e dos novos estudos sobre a mente humana.

O Livro dos Espíritos foi o primeiro livro que deu origem a codificação dessa doutrina que se diz ciência, filosofia e religião. Esse livro foi lançado no dia 18 de abril de 1857 em Paris por Allan Kardec. As demais obras foram publicadas entre um intervalo de dois a três anos de uma para outra como em uma sequencia de informações. Alguns estudos afirmam que essas cinco obras foram preparadas para serem publicadas em um único livro dividido apenas por capítulos, mas não foi isso que ocorreu.

Buscando provar a relação e existência entre o mundo físico e o espiritual, as obras de Kardec teriam sido escritas por ordem e sob o ditado de espíritos superiores. Portanto, ao autor, nada mais coube do que a realização da codificação dessas obras.

Assim, foram-se delineando os termos que compõem a doutrina, pois, como o próprio Kardec inicia sua obra: "Para as coisas novas necessita-se de palavras novas, assim o que quer a clareza da linguagem para evitar confusão inseparável do sentido múltiplo dos mesmos vocábulos." (KARDEC, 2009[1857]- p.7).

Pretende-se aqui demonstrar a necessidade de organização de uma Terminologia Espírita a partir do levantamento dos termos criados pelos 
espíritos que guiaram Allan Kardec com $\circ$ intuito de explicar fenômenos ou coisas já existentes e ainda não nomeados ou até mesmo nomeados, mas com outras significações, gerando ambiguidades de interpretação, nas cinco obras que iniciaram a codificação espírita: $O$ Livro dos Espíritos (1857), O Livro dos Médiuns (1859), O Evangelho Segundo o Espiritismo (1863), O Céu e o Inferno (1865) e A Gênese (1868). Termos estes que deram ao Espiritismo uma terminologia específica que, até então, não se tem conhecimento de sua compilação em uma única obra.

\section{O surgimento da doutrina espirita}

No dia trinta e um de março de 1848, em Hydesville, vilarejo situado próximo da cidade de Rochester, rio condado de Wayne, no Estado de Nova lorque, nos Estados Unidos, uma família de tradição metodista, começou a ouvir pancadas em sua casa. Tratava-se da família Fox, uma família protestante composta de: John Fox, sua esposa Margareth e as filhas menores Margareth e Catherine (Kate Fox). As filhas do casal possuíam - que hoje chamamos de mediunidade de efeitos físicos, ou seja, elas conseguiam se comunicar com os espíritos dos mortos e fazerem barulhos a partir da influência desses espíritos. Assim a História registra o início do Espiritismo nos povos de língua inglesa, conhecido inicialmente como o Novo Espiritualismo.

Em 1850, já na Europa, os salões de Paris começaram a servir de diversão aos seus frequentadores com episódios de fenômenos sobrenaturais: mesas começavam a girar sem que houvesse explicações para esse movimento. Juntamente à grande reforma parisiense que a partir de 1850 começava a ganhar ares cosmopolitas com ruas e avenidas largas, novos parques e tempo de revolução industrial e descobertas científicas, o homem que se sentia capaz de explicar e interferir nos fenômenos ao seu redor, se deparou com as "mesas girantes" que não tinham explicações científicas. $E$, apesar de toda a modernidade, eram frequentes as reuniões em salões culturais ou mansões da alta sociedade para fazer as mesas girarem apenas com a concentração dos frequentadores. Nobres, intelectuais e poetas, dentre eles Victor Hugo, frequentador assíduo, enchiam os salões em torno de uma mesa vazia, esperando-a girar.

O fenômeno das mesas girantes a cada dia se tornava mais sensação nas diversas partes do planeta: América do Norte, em toda a Europa, mas 
principalmente em Paris. Foi nesse período que o professor Hippolyte Léon Denizard Rivail que, mesmo vivendo em Paris, ainda não tinha ouvido falar nos prodígios das mesas, começa a se dar conta desses fenômenos. Respeitado nos círculos educacionais e científicos, possuidor de conhecimentos em diversas áreas do saber humano, autor de livros e tratados que versavam desde gramática à aritmética, o discípulo do pedagogo Pestalozzi que era um grande magnetizador, estudioso e praticante das técnicas desenvolvidas por Mesmer para a cura através dos fluidos magnéticos, começa a se interessar pelas mesas girantes.

Foi assim que um grande amigo seu, o Sr. Fortier, o convidou para ir a uma sessão de magnetismo na casa do Sr. Roger, onde seria magnetizada a Sra. Roger, que apesar de sonâmbula era lúcida e nos momentos de transe era capaz de fazer diagnósticos precisos das mais diversas enfermidades.

Em uma tarde de dezembro de 1854, antes de a sessão começar, a conversa acerca do fenômeno das mesas girantes, levou o professor Hyppolite e o Sr. Fortier a deduzirem que as causas dos movimentos das mesas poderiam ser o próprio fluido magnético dos presentes. Porém, na semana seguinte, ocorreu novo encontro na residência do Sr. Roger. $\bigcirc$ Sr. Fortier informou então que as mesas não só giravam como também respondiam às perguntas dos consulentes. Ainda assim, o professor Rivail não se deixou impressionar, sendo cético e necessitando de suas próprias experiências para crer no fenômeno: era o posicionamento do cientista que não se deixava impressionar pelo que ouvia.

Semanas depois, mais precisamente em janeiro de 1855, outro amigo, o Sr. Carlotti informou ao professor Rivail que o movimento das mesas girantes se dava por espíritos mortos, ou, no seu dizer, "almas dos defuntos". Mais uma vez o professor duvidou do que ouvira.

E no dia primeiro de maio de 1855, uma terça-feira às vinte horas, na casa da família Roger, o Prof. Rivail em companhia do Sr. Fortier, o magnetizador da sonâmbula, a Sra. Roger, presencia a primeira manifestação espiritual. Lá se encontrava também o Sr. Pâtier, um funcionário público, já idoso e muito instruído que o havia convidado a assistir às experiências que se realizavam na casa da Sra. Plainemaison, à rua Grange-Batelière, 18. E também a Sra. Plainemaison. O Professor Rivail presenciou o fenômeno das mesas que giravam, saltavam e corriam, em tais condições que não deixavam margem para qualquer dúvida. Esse fato levou o professor a estudar a fundo o fenômeno.

Em uma das reuniões na casa da Sra. Plainemaison, o professor Rivail conheceu a família Baudin e foi convidado para assistir às sessões 
que se realizavam em sua casa. A partir daí, Rivail tornou-se frequentador assíduo presenciando as filhas do casal, Caroline de dezesseis anos e sua irmã Julie, de catorze anos, realizando comunicações contínuas e respostas a perguntas formuladas, que de modo evidente revelavam a intervenção de uma inteligência estranha.

A partir daí, o professor Rivail se utiliza do método experimental, característico da época, para entender os fenômenos presenciados. Assim, em primeiro de janeiro de 1856 as reuniões tomaram um novo rumo na residência da família Baudin. O início dos trabalhos passou a ser feito com uma prece e espíritos superiores compareciam às sessões respondendo às perguntas formuladas por Rivail que tratavam de assuntos profundos sobre todas as áreas do saber humano.

Em março de 1856, a jovem Caroline manifesta o seu guia espiritual: - Espírito Verdade. No mês seguinte, outra médium ${ }^{41}$, Ruth Celine Japhet, recebe uma comunicação do Espírito Verdade, dizendo ao professor de sua grande missão, a qual foi confirmada pelo mesmo espírito em junho de 1856, na casa do Sr. Carlotti, através de outra jovem médium, Aline Carlotti.

E assim deu-se início aos trabalhos da codificação espírita com a primeira publicação e cujos primeiros exemplares saíram da Tipografia de Beau, em Saint-Germain-en-Laye, cidade vizinha a Paris no dia dezoito de abril de 1857: O Livro dos Espíritos, organizado em cerca de 20 meses pelo professor Rivail, que coordenou longas reuniões com médiuns, fazendo perguntas a eles e colhendo respostas que acreditava vir dos espíritos. Dos vários médiuns que contribuíram para o livro, três jovens se destacaram: Julie e Caroline Baudin, de quinze e dezoito anos, respectivamente, e Ruth Celine Japhet, de vinte.

Organizando as respostas para 501 perguntas sobre o Universo, Kardec criou a doutrina e visão de mundo do Espiritismo, indo muito além de uma diversão da burguesia parisiense. Essa primeira edição com apenas 176 páginas e 501 questões, foi comercializado pela livraria Dentu, localizada na galeria d'Orléans, no Palais Royal, em Paris. No dia dez de março de 1860, surge a segunda e definitiva edição, amplamente revista e ampliada e já com o concurso de outra médium, Ermance Dufaux, com 1018 questões.

Para evitar que sua autoridade e fama de autor prevalecessem na obra, o professor Hyppolite Rivail optou por adotar um pseudônimo. Assim, em combinação com os espíritos, decidiu adotar o nome que tivera em outra vida, como druída, nas Gálias: Allan Kardec. Também optou por suprimir o ${ }^{41}$ Indivíduo que serve de mediador da comunicação entre o mundo dos vivos e dos mortos. 
nome dos mais de dez médiuns que prestaram seu concurso à obra, evitando assim que fossem alvo de críticas e perseguições, como aconteceram às jovens da família Fox, nos Estados Unidos. Quanto ao título do livro, uma vez que não se considerava autor e sim um organizador, deu o nome de $\bigcirc$ Livro dos Espíritos. Estava criado assim o primeiro livro e, com ele, uma nova religião para os homens.

\section{0 corpus de base: os livros da codificação espírita}

Primeiro de uma série de cinco livros ${ }^{42}$ editados pelo pedagogo sobre o mesmo tema, surge $O$ Livro dos Espíritos, publicado em uma época de grandes transformações sociais, filosóficas, políticas e linguísticas, período do surgimento das ciências e de novos estudos sobre a mente humana.

Organizado sobre a forma de perguntas e respostas, a obra contém em sua primeira edição de 1857, 501 perguntas seguidas das respostas. Em 1860, uma segunda edição é publicada revista e aumentada, contendo a parte suplementar que fora anunciada na primeira edição com as questões que não foram organizadas na primeira. Nesta edição as questões passam de 501 para 1018 e é considerada pelo próprio autor como uma obra nova. Desde a $1^{a}$ questão: "Quem é Deus?" à 1018 "Jamais o reino do bem poderá ter lugar sobre a Terra?", as respostas são dadas pelos espíritos supracitados através da escrita através de um médium denominada psicografia indireta. ${ }^{43}$

Inicialmente duas irmãs, jovens médiuns, Caroline e Julie Boudin, ambas dezesseis e catorze anos, respectivamente, iniciaram o trabalho de psicografia indireta a partir de cestinhas-de-bico ${ }^{44}$. Mais tarde, pelo mesmo 42 1857: O Livro dos Espíritos; 186 1- O Livro dos Médiuns; 1864- O Evangelho segundo o Espiritismo; 1865- O Cév e o Inferno; 1867- A Gênese.

43 Ocorre quando o lápis é adaptado a um objeto qualquer que serve, de certo modo, de apêndice à mão, como uma cesta, uma prancheta, etc., diferente da psicografia direta mais utilizada atualmente em que o próprio médium escreve segurando o lápis ou objeto escrevente.

${ }^{44}$ Espécie de cestinha escrevente em o médium transcrevia pela escrita a comunicação dos espíritos. Enfiava-se um lápis através do fundo de uma cestinha e o firmava bem, com a ponta de fora e voltada para baixo, a mantendo em equilíbrio sobre a ponta, numa folha de papel, pondo os dedos na borda 
processo, outra jovem, Ruth Celine Japet de dezoito anos realizou o processo mediúnico para a revisão do livro. Outros médiuns foram posteriormente consultados passando de dez o número dos mesmos, cujos textos psicografados contribuíram para a estruturação d' $O$ Livro dos Espíritos. Enfim, as perguntas foram respondidas, mas passaram por revisões de outros espíritos no intuito de confirmar a veracidade das respostas.

Até o desencarne de Allan Kardec, O Livro dos Espíritos já estava em sua $16^{a}$ edição. Pelo menos entre a primeira e segunda edição, tudo indica que houve ao menos a intenção de publicar uma nova edição. Isso se deve ao fato de, ao final da primeira edição, Kardec ter publicado um sumário dos capítulos d' $O$ Livro dos Espíritos que não corresponde a nenhuma das duas edições. Ela é considerada uma edição perdida e teria sido publicada pela mesma editora da primeira edição, a Dentu. Atualmente, o livro passa de 200 edições publicadas nas mais diversas línguas em diferentes lugares do nosso planeta.

Segundo Adenaver:

- Livro dos Espíritos foi, dentre os livros espíritas editados, o primeiro cujo conteúdo trouxe a síntese do conhecimento espírita... Não é obra de um ser humano, mas de vários espíritos desencarnados que inauguraram uma nova era da humanidade, a Era do Espírito. (NOVAES, 2003)

Quanto aos originais da obra de Kardec, até então não se tem conhecimento de onde foram parar. Mesmo querendo criar uma sociedade impessoal para as obras por ele codificada, Kardec morreu antes de concretizar sua proposta. Assim, as obras que deveriam fazer parte do Espiritismo, tornaram-se herança familiar e após a sua morte ficaram com sua esposa, Amelie Boudet. Posteriormente, os originais foram entregues a Pierre-Gaëtan Leymarie, sócio e um dos maiores seguidores de Kardec que após sua morte, manteve-se em atividade defendendo o Espiritismo por trinta anos. Graças a ele, as obras de Kardec foram traduzidas e divulgadas para diversos lugares do mundo.

De tudo que recebeu das mãos da esposa de Kardec, Leymarie publicou: uma parte na Revue Espirite, periódico dirigido por Kardec até o

da cesta para ela se movimentar e o lápis escrever. Atualmente a comunicação com os espíritos se dá pela psicografia direta, ou seja, pelo próprio punho do médium. 
seu falecimento, cuja função era a divulgação da doutrina espírita, lançado por Allan Kardec com recursos próprios, em primeiro de janeiro de 1858 na cidade de Paris; outra parte transferida para os livros da Codificação Espírita; outra utilizada em Obras Póstumas que traz uma biografia de Kardec publicada originalmente na Revue Spirite, assim como o discurso proferido pelo astrônomo Camille Flammarion no sepultamento de Kardec. Dividida em duas partes, contém diversos artigos escritos por Kardec que não haviam sido publicados, e ainda transcrições de várias comunicações mediúnicas ocorridas em reuniões em que Kardec participou; a outra parte não se sabe ao certo, mas é possível que tenham vindo para o Brasil, onde Leymarie esteve exilado em 1851.

Desde essa época, não se sabe ao certo o destino dos documentos que teriam vindo para o Brasil: poderiam ter sido trazidos por Leymarie e serem arquivados nos porões da Federação Espírita do Brasil; poderiam ter sido queimados por soldados alemães para aquecê-los durante o inverno quando ficaram aquartelados na Casa dos Espíritas na França; e ainda poderiam ter sido colocados nas mãos de Silvino Canuto de Abreu, profundo conhecedor do Espiritismo no Brasil e no mundo, em 1939, um ano antes da invasão alemã na França. Pesquisador espírita brasileiro que trabalhava na embaixada brasileira em Paris, Canuto teria fugido com a documentação para o Brasil tentando salvá-la da invasão alemã uma vez que teria sido avisado de tal invasão pelos espíritos. Mas, mesmo que isso tivesse acontecido, tais documentos teriam se perdido entre os seus descendentes. Todas essas histórias sobre os famosos documentos tão cuidadosamente arquivados e citados por Kardec, não conseguiram mudar o destino desconhecido e obscuro de tal obra.

Atualmente, o Espiritismo vem se expandindo por todos os cantos do planeta, mas é no Brasil que compreende o maior número de adeptos podendo-se considerar a nossa nação como a que comporta atualmente o maior número de espíritas do mundo.

\section{O dicionário terminológico espírita: proposta teórica}

Entende-se dicionário aqui como: "Conjunto de vocábulos de uma língua ou de termos próprios de uma ciência ou arte, dispostos, em geral, alfabeticamente, e com o respectivo significado, ou a sua versão em outra 
língua." (FERREIRA, 1986).

Elaborar um dicionário vai muito além de elencar palavras e definílas. Conforme Borba nos mostra:

Um dicionário nunca deve ser tomado apenas como um simples repositório ou acervo de palavras, ao contrário, deve ser um guia de uso e, como tal, tornar-se um instrumento pedagógico de primeira linha. Isso se torna crucial quando se focaliza a função da interação social da linguagem, o que permite avaliar a importância da língua para qulaquer comunidade." (BORBA, 2003).

Logo, fica claro que elaborar um dicionário não é apenas dispor as palavras de uma língua em ordem alfabética e defini-las. Existem elementos teóricos que devem nortear a montagem de um dicionário de uma língua. Além disso, existem diversas tipologias de dicionários.

O dicionário terminológico é uma dessas possibilidades, fazendo um recorte na língua geral e trazendo vocábulos específicos e utilizados em contextos específicos.

À luz da Terminologia, ramo da Lexicologia que estuda os termos e a organização das linguagens especializadas, e dos recursos que se têm disponíveis para o estudo das palavras, buscar-se-á levantar e compreender as criações lexicais da doutrina espírita a partir das cinco obras que Kardec deixou para a posteridade estabelecendo os princípios básicos da doutrina espírita, mesclando conceitos filosóficos e religiosos com algumas terminologias científicas do século XIX.

Foi preciso que se crie uma terminologia específica para coisas que ainda não haviam sido nomeadas, apesar dessas coisas já existirem desde o início dos tempos. Dessa forma, Kardec, ao codificar a Doutrina Espírita, deu-lhe um caráter próprio, precisando muitas vezes, além de criar novas palavras, dar novos significados às já existentes, ao comparar a versão espírita com as correntes espiritualistas existentes, buscando sempre demonstrar as diferenças entre elas.

A necessidade de se organizar, elencar e estudar a utilização e significação das palavras de uma língua deve ter sido a mola propulsora que deu início aos estudos lexicais. A linguagem é um conjunto de tradições, histórias, aprendizagens e crenças que uma pessoa vai construindo ao longo de sua existência, mas que também corresponde a um aprendizado coletivo. Ainda que a língua seja individual, ela faz parte de uma comunidade que se 
expressa de acordo com a sua história linguística.

Para se compreender uma palavra enquanto termo, é necessário se fundamentar na dimensão conceitual do signo linguístico enquanto conteúdo especializado. Logo, a ênfase ao componente conceitual da terminologia faz com que os termos sejam compreendidos enquanto unidades de conhecimento, excluindo-se a unidade linguística dos mesmos. Dessa maneira, o termo é entendido em uma perspectiva comunicacional e cognitiva.

A necessidade de se abranger os estudos tomando como base a teoria linguístico-comunicativa demostra a abrangência do processo comunicativo e suas implicações em decorrência do funcionalismo linguístico. Segundo Krieger (2001, p. 27), "As novas tecnologias, ao contrário das pioneiras nomenclaturas, instituem-se, na sua maioria, em consonância com o léxico comum". comum". Logo, não podemos falar em exclusividade do termo, ainda que seja em terminologia. Isso não condiz com a realidade, uma vez que esses termos ultrapassam as fronteiras das ciências e chegam ao cotidiano social.

Mesmo sabendo que muitas unidades lexicais permanecem no âmbito das ciências, a complexidade de delimitação de fronteira entre léxico comum e profissional é muito difícil de ser estabelecido uma vez que o conhecimento científico atinge o dia-a-dia da sociedade.

Interessante observar que a terminologia do Espiritismo, uma doutrina que, apesar de se dizer ciência, atinge com maior ênfase o campo das crenças e filosofia, foi elaborado por um professor que teve o mesmo pensamento do fundador da Teoria Geral da Terminologia, Eugen Wuster que entendia o termo como um instrumento de trabalho cuja proposta era a de desfazer ambiguidades de compreensão: "Para as coisas novas necessita-se de palavras novas, assim o quer a clareza a linguagem para evitar confusão inseparável do sentido múltiplo dos mesmos vocábulos." (KARDEC, 2009[1857]- p.7). O ideal da língua deve ser esse, evitar ambiguidade, mas isso está muito longe de ser o real. $\bigcirc$ próprio termo utilizado por Kardec para definir a sua doutrina e evitar ambiguidade de sentido como outras crenças espiritualistas, espiritismo, é tomado hoje no sentido amplo do termo e não mais como Kardec propôs no século XIX. Ser espírita hoje não significa exatamente seguir a codificação de Kardec. Existem diversas religiões espiritualistas que se intitulam espíritas mesmo sem serem kardecistas. Tudo o que seu fundador não queria.

É importante salientar que, diante da polissemia da palavra Terminologia, torna-se necessário esclarecer que a proposta desta pesquisa 
será a de estudar a Terminologia tomando como base a perspectiva linguística que, diferente da perspectiva clássica introduzida por Eugen Wüster que defende a univocidade entre o conceito e seu respectivo termo, baseia-se nos estudos terminológicos atuais que compreendem as relações de sentido da palavra também como uma realidade da linguagem técnico-científica, conforme já ocorrem nos discursos não especializados. Esse fato poderá aproximar também a pesquisa dos estudos de criação de palavras, uma vez que a maioria dos neologismos de uma língua faz parte de termos de especialidades que posteriormente poderão fazer parte da língua comum, formando analogias e associações linguísticas.

Fazendo uma relação entre a inevitabilidade do surgimento dos termos a partir do surgimento de uma nova ciência, teoria, religião ou até mesmo esporte, podemos observar que Allan Kardec pensava como os linguistas a exemplo de Emile Benveniste. Ambos percebem a necessidade do surgimento de novas palavras para novas coisas que vão surgindo: "Uma ciência somente começa a existir ou a ser divulgada à medida que impõe seus conceitos e divulga-os por meio de suas respectivas denominações." (BENVENISTE, 1974). "Para exprimir os fenômenos especiais dessa ciência, foram precisos termos especiais. O Espiritismo tem, de hoje em diante, sua nomenclatura, assim como a química tem a sua." (KARDEC [1863] 2005, p. 29-30).

Enfim, para se fazer entender, ao codificar as propostas de uma nova forma de entender a relação entre vivos e mortos, Allan Kardec em suas obras criou palavras para explicar fenômenos que sempre existiram, mas que as lexias existentes não davam conta de suas significações. Assim, foram-se delineando os termos que compõem tal doutrina.

Dessa forma, busca-se aqui trazer à tona as lexias criadas pelos espíritos que guiaram Kardec, com o intuito de explicar fenômenos ou coisas já existentes e ainda não nomeadas como espiritismo, reencarnação, perispírito; ou até mesmo nomeadas, mas com outras significações, gerando ambiguidades de interpretação como alma, médium, passe etc.

O resgate da identidade e história de um povo partindo-se dos estudos linguísticos e lexicais nos leva a conhecer perspectivas e processos de evolução da alma humana na busca do entendimento de sua origem e de seu destino. Allan Kardec em suas obras não apenas criou palavras, como também as definiu de maneira que a doutrina por ele codificada fosse 0 menos ambígua possível.

O resgate da identidade e história de um povo partindo-se dos estudos linguísticos e lexicais nos leva a conhecer perspectivas e processos 
de evolução da alma humana na busca do entendimento de sua origem e de seu destino.

Os estudos lexicais perpassam por diversas possibilidades. Dentre elas, a da representação dos sentidos dos enunciados, estudada pela Semântica, que servirá como referencial teórico dessa pesquisa. Conforme dita o célebre Dicionário de Linguística do Professor Jean Dubois:

\section{A teoria semântica ${ }^{45}$ deve explicar as regras gerais que condicionam a interpretação semântica dos enunciados, como a teoria fonológica deve explicar as regras fonológicas universais, das quais as línguas não utilizam, senão um subconjunto. (DUBOIS, 1973)}

Ao surgir uma nova ciência ou uma nova coisa, novas palavras surgem juntas para dar conta de suas definições. Dessa forma, novos termos foram criados para explicar um novo dogma dando origem a uma terminologia específica do Espiritismo.

Espera-se com tal proposta, conseguir realizar um vocabulário de termos espíritas, abrangendo as obras que deram início à codificação espírita, contribuindo assim para tornar cada vez mais científicas e claras as propostas dessa doutrina.

\section{Considerações fincis}

A Lexicologia é um caminho seguro para se entender a história de um povo, partindo-se do estudo do seu vocabulário. $\bigcirc$ acervo lexical de um povo é construído ao longo de sua história social, política, econômica, religiosa. Não há mais dúvida de que o estudo lexical de uma língua nos remete à história, cultura, costumes e crenças de quem utiliza essa língua. Em cada época as palavras se modificam, se ajustam, se acoplam, são esquecidas, são relembradas, são criadas, diversificando o seu sentido de acordo com a época vigente, sendo proibida e permitida de acordo com a sociedade em que esteja inserida.

Todos esses caminhos dão aos estudos lexicológicos, a possibilidade de estudar as palavras de uma língua nas mais diversas perspectivas. $\bigcirc$ resgate da identidade e história de um povo partindo-se dos estudos linguísticos

45 Grifo do autor. 
e lexicais nos leva a conhecer perspectivas e processos de evolução da alma humana na busca do entendimento de sua origem e de seu destino. Toda língua, assim, precisa de novas criações, além das diversas lexias existentes, para que se evitem a polissemia e a ambiguidade de sentidos. Dessa forma, busca-se a partir dos estudos lexicais, contribuir com a história da humanidade e com a busca de uma melhor clareza nas definições que permeiam os diversos campos do conhecimento humano. 


\section{Referências Bibliográficas:}

ABBADE, Celina Márcia de Souza. O Estudo do Léxico. In: Diferentes Perspectivas dos Estudos Filológicos. Salvador: Quarteto, 2006. p. 213-225.

BARBOSA, Maria Aparecida. Lexicologia: aspectos estruturais e semânticosintáticos. In: PAIS, Cidmar Teodoro et al. Manual de linguística. Petrópolis: Vozes, 1978.

BORBA, Francisco da Silva. Organização de dicionários: uma introdução à lexicografia. São Paulo: UNESP, 2003.

COSERIU, Eugenio. Gramática, semántica, universales estudios de la linguística funcional. 2 ed. rev. Madrid: Gredos, 1987.

GAARDER, Jostein. HELLERN, Victor. NOTAKER, Henry. O Livro das religiões. Trad. Isa Mara Lando. São Paulo: Companhia as Letras, 2000.

KARDEC, Allan. O Livro dos espíritos. Trad. de Salvador Gentile; rev. Elias Barbosa. Araras: IDE, 2009. 182 ed.

O evangelho segundo o espiritismo. Trad. de Salvador Gentile; rev. Elias Barbosa. Araras: IDE, 1999. 238 ed.

Obras póstumas: é preciso propagar a moral e a verdade. Trad. de Maria Lucia A. Carvalho. Rio de Janeiro: CELD, 2002.

A minha primeira iniciação no espiritismo. In: Obras póstumas. 29. ed. Rio [de Janeiro]: FEB, [199-].

NOVAES, Adenauer Marcos Ferraz. Conhecendo o espiritismo: um curso básico. Salvador: Fund. Lar Harmonia, 2003.

REVISTA ESPÍRITA. São Paulo: LAKE, 1858.

ULMANN, Stephen. Semântica: uma introdução à ciência do significado. Trad. de J. A. Osorio Mateus. 2. ed. Lisboa: Calouste Gulbenkian, 1970.

VILELA, Mário. Estudos de lexicologia do português. Coimbra: Almedina, 1994. 